\title{
"A design framework for enhancing engagement in student-centered learning: own it, learn it, and share it" by Lee and Hannafin (2016): an international perspective
}

\author{
Kevin M. Wong ${ }^{1}$ (D)
}

Accepted: 1 October 2020 / Published online: 9 October 2020

(c) Association for Educational Communications and Technology 2020

\begin{abstract}
This commentary is written in response to the manuscript entitled "A design framework for enhancing engagement in student-centered learning: own it, learn it, and share it" (Lee and Hannafin in 64: 707-734, 2016) and offers an international perspective. To enhance student engagement in student-centered classrooms, Lee and Hannafin $(64: 707-734,2016)$ argue that learners need to be empowered with autonomy, scaffolding, and authentic audiences, manifested in an "own it, learn it, share it" design framework. This commentary examines how each of these frameworks might be implemented with the "shift to digital" learning, and considers how these guidelines might be adopted in international contexts. While owning, learning, and sharing are principles that can be appreciated by systems of education around the globe, the very definitions and understandings of owning, learning, and sharing knowledge need to be carefully considered in light of cultural differences. The commentary concludes with a call for future research to closely examine what student-centered learning in online environments might look like in different contexts.
\end{abstract}

Keywords Student centered learning $\cdot$ Student engagement $\cdot$ Shift to digital · Internationalperspective $\cdot$ Multicultural perspective

\section{Introduction}

Student-Centered Learning (SCL) is a paradigm that places students in the driver's seat of the learning process, allowing them to decide for themselves what they need to learn and how they might learn it (Glasgow 1997). Around the world, SCL is adopted by many schools and education systems that promote problem-based learning, project-based learning, case-based learning, and inquiry learning (Lee and Hannafin 2016). Drawing from constructivist, constructionist, and self-determination theories, Lee and Hannafin (2016) propose that SCL cultivates student engagement through key constructs of autonomy, scaffolding, and audience. Specifically, autonomy empowers students with control over

Kevin M. Wong

kevin.wong@pepperdine.edu

1 Graduate School of Education and Psychology, Pepperdine University, 6100 Center Drive,

Los Angeles, CA 90045, USA 
their learning (Dochy et al. 2003); scaffolding creates a strategic pathway for learning (Vygotsky 1978); and authentic audiences provide students with purpose and accountability for learning (Kearney and Schuck 2006). While these constructs are critical foundations of SCL represented in international scholarship, one limitation of Lee and Hannafin's (2016) article is to consider how autonomy, scaffolding, and audience may differ according to cultural or linguistic context.

From an international, multicultural perspective, SCL is a field of educational research that is consistently studied in a variety of sociocultural contexts. Scholars and practitioners alike engage in research to better understand how motivation and self-regulationkey components of SCL—can be incorporated into diverse classrooms with the goal of empowering learners from early childhood classrooms (Nair 2019), to English as a Foreign Language classrooms (Mak and Wong 2018), to special education classrooms (Pederson and Liu 2003). In their article, Lee and Hannafin (2016) propose a design framework to enhance engagement within SCL, which they term "Own it, Learn it, Share it." With the Shift to Digital movement during COVID-19 that resulted in teaching and learning online, this proposed framework presents promising opportunities to enhance student engagement in virtual classroom spaces. Specifically, it offers timely principles that inherently promote student-centeredness when the abrupt move to digital learning resulted in predominantly teacher-centered pedagogy (Moorhouse 2020).

Own It, Learn It, Share It provides a number of practical applications that educators and scholars can consider in digital learning environments. In brief, Lee and Hannafin (2016) propose to increase student engagement by enhancing student autonomy (i.e. Own it), cultivating metacognition throughout the learning process (i.e. Learn it), and empowering students to engage their work with a meaningful audience (i.e. Share it). Although technology is only explicitly referenced in the "Learn It" stage of the design framework, it can be applied to all design assumptions.

To foster autonomy and "own" specific learning initiatives, the first guideline proposes that teachers facilitate student endorsement of external goals. Teachers create space for students to set specific goals with choices that are relevant and applicable to their lives. This may be done in digital environments through synchronous videoconferencing systems or asynchronous learning management systems. Adopting an international, multicultural perspective highlights a limitation of Lee and Hannafin's (2016) article whereby educators may note that "owning" a learning initiative may vary from one cultural context to the next. In education systems with high stakes assessments that strongly influence curriculum design and day-to-day instruction, student ownership or autonomy may be limited with prescribed goals for students to choose from. For example, in Hong Kong where teachers often prepare students for school-based and territory-wide assessments during classroom instruction, teachers may ask students to "own" a particular writing assignment by choosing from a select list of writing goals (Mak and Wong 2018). While this may foster autonomy among the learner, it can significantly contrast with other school systems that provide students with more freedom to "own" and develop their writing skills.

To cultivate metacognition in the "Learn It" phase, design guidelines suggest that teachers provide guidance on how to engage in the learning process and provide support to students as they monitor progress. Technology plays a critical role in this phase as students need to reflect on what they know and don't know (i.e., metacognition) and seek resources - often through technology — to address their gaps in knowledge. With the shift to digital, students with access to resources at home demonstrate learning progress on asynchronous platforms or during synchronous meetings with educators. The privilege of access to educational technology, however, is not equally distributed in countries 
around the world. A constraint to Lee and Hannafin's (2016) framework is considering for whom SCL might easily benefit. Disparities in access to technology continue to exist both between and within nations (Flack et al. 2020), interrupting the formal education of certain communities at disproportionate rates (Gonzalez 2016). Educators, in response, have the added responsibility of providing access to materials to facilitate independent learning, or to offer explicit guidance to develop digital literacy. Future research may also consider implications for education systems in the Global South.

Lastly, to enhance engagement through the "Share It" phase, Lee and Hannafin (2016) propose that educators promote dialogue among students and audiences while also facilitating peer review. Online environments provide unique opportunities and challenges for students to share work. On the one hand, students can speak to a larger audience if their learning is published in public domains. Knowing their work will be shared more broadly, in turn, affects how students own and learn activities. On the other hand, sharing work only through digital platforms limits students from skills that are more readily fostered in inperson environments (i.e., voice projection, reacting to a live audience in a room). Importantly, from an international perspective, educators must consider how different cultures value and understand the notion of sharing. For example, in countries that value saving face - the desire to maintain respect and avoid humiliation in public spaces-sharing may bring added or unnecessary stress and shame that is detrimental to the learning process.

This commentary briefly examines Lee and Hannafin's (2016) framework for enhancing engagement through owning, learning, and sharing, from an international perspective. With the sudden shift to digital in classrooms around the world, future research may continue to examine how student engagement varies from context to context to understand how educators can better support all students.

\section{Compliance with Ethical Standards}

Conflict of interest There are no potential conflicts of interest.

Research involving human participants and/or animals This research submission does not involve human participants and/or animals.

Informed consent Informed consent was not required for this study.

\section{References}

Dochy, F., Segers, M., Van den Bossche, P., \& Gijbels, D. (2003). Effects of problem-based learning: A meta-analysis. Learning and Instruction, 13, 533-568.

Flack, C. B., Walker, L., Bickerstaff, A., \& Margetts, C. (2020). Socioeconomic disparities in Australian schooling during the COVID-19 pandemic. Melbourne, Australia: Pivot Professional Learning.

Glasgow, N. A. (1997). New curriculum for new times: A guide to student-centered, problem-based learning. Thousand Oaks, CA: Corwin.

Gonzales, A. (2016). The contemporary US digital divide: from initial access to technology maintenance. Information, Communication \& Society, 19(2), 234-248.

Kearney, M., \& Schuck, S. (2006). Spotlight on authentic learning: Student developed digital video projects. Australasian Journal of Educational Technology, 22(2), 189-208.

Lee, E., \& Hannafin, M. J. (2016). A design framework for enhancing engagement in student-centered learning: own it, learn it, and share it. Educational Technology Research and Development, 64(4), 707-734.

Mak, P., \& Wong, K. M. (2018). Fostering self-regulated learning through portfolio assessment in the writing classroom. English Language Teaching Journal, 72(1), 49-61. https://doi.org/10.1093/elt/ccx012. 
Moorhouse, B. L. (2020). Adaptations to a face-to-face initial teacher education course 'forced' online due to the COVID-19 pandemic. Journal of Education for Teaching. https://doi.org/10.1080/02607 476.2020.1755205.

Nair, P. (2019). Blueprint for tomorrow: Redesigning schools for student-centered learning. Harvard Education Press.

Pedersen, S., \& Liu, M. (2003). Teachers' beliefs about issues in the implementation of a student-centered learning environment. Educational Technology Research and Development, 51(2), 57.

Vygotsky, L. S. (1978). Mind in society: The development of higher mental process. Cambridge: Harvard University Press.

Publisher's Note Springer Nature remains neutral with regard to jurisdictional claims in published maps and institutional affiliations.

Kevin M. Wong is an Assistant Professor in the Graduate School of Education and Psychology at Pepperdine University. He seeks educational equity for linguistically and culturally diverse students in pre-kindergarten to grade 12 international contexts. His current research investigates dual-language bilingual education programs, language policies for multilingual education, vocabulary learning through educational media, and teaching and learning during COVID-19. 